\title{
Relevant Aspects of Expert Interest in the Perception of the Facial Aesthetic Damage
}

\author{
Luiz Eugênio Nigro Mazzilli ${ }^{1}$, Nelson Massanobu Sakaguti ${ }^{*}{ }^{\circledR}$, Mário Marques Fernandes ${ }^{1}$, \\ Juan Antonio Cobo Plana ${ }^{2}$, Fernanda Capurucho Horta Bouchardet ${ }^{1}$, \\ Rogério Nogueira de Oliveira ${ }^{1}$
}

${ }^{1}$ Forensic Dentistry, Department of Social Dentistry, University of São Paulo, São Paulo, Brazil

${ }^{2}$ Institute of Legal Medicine, Zaragoza, Spain

Email: ^nsakagut@usp.br

How to cite this paper: Mazzilli, L.E.N., Sakaguti, N.M., Fernandes, M.M., Plana, J.A.C., Bouchardet, F.C.H. and de Oliveira, R.N. (2020) Relevant Aspects of Expert Interest in the Perception of the Facial Aesthetic Damage. Forensic Medicine and Anatomy Research, 8, 1-10.

https://doi.org/10.4236/fmar.2020.81001

Received: October 23, 2019

Accepted: November 11, 2019

Published: November 14, 2019

Copyright $\odot 2020$ by author(s) and Scientific Research Publishing Inc. This work is licensed under the Creative Commons Attribution International License (CC BY 4.0).

http://creativecommons.org/licenses/by/4.0/

\begin{abstract}
Forensic aesthetic facial damage-AFD expert's valuation is a concerning matter in court as expressively vary in between experts. In fact, differences can be quite significant suggesting examiners age, sex and professional qualification may influence this valuation. Aiming to offer a systematic and more objective evaluation, some methods for assessing AFD had been proposed lately. Known as Aesthetic Impairment Impact Perception (AIPE), CoboPlana's revised methodology (2010) was idealized to minimize the examiner's subjectivity by means of answering an ordered sequence of questions related to the specific damage perception. This research aims to access AFD perception differences (simulated cases) in between Lawyers, Heath professionals (Physicians and Dental surgeons) and general professionals (laypeople) under AIPE methodology in order to allow a better comprehension of AFD when dealing with forensic expertise cases. Within Groups perceptions varied $(\mathrm{p}<$ 0.05 ) when evaluating lesions below "important" severity grade. Raters over 35 Years age scored higher AFD lesions, and rater's sex (as an independent variable) did not express any significant difference in AFD scoring. The tendency of under-rating AFD lesions below very important severity grade was observed being a matter of major concern considered their prevalence and the effective consequences involved to the victim. These results recommend extra caution when performing AFD evaluation and consequently expertise reports, claiming a more judicious analysis based on consolidated standards and suggest, examiners to be more perceptive to physical damage evaluation in order to include social perceptions and reactions, mainly, victims feelings and constrains over their aesthetic loss.
\end{abstract}

\section{Keywords}

Aesthetic Facial Damage, Aesthetic Facial, Damage, Society 


\section{Introduction}

The prevalence of oral and maxillofacial trauma increased in the last decades following a growing trend in traffic and labor accidents, urban violence and even professional malpractice. In many cases, these traumas consolidate with evident sequels-expressed clinically as scars [1] assessing and quantifying aesthetic facial damage (AFD) in Court frequently results controversial reports even considered experienced professional expertise [2]. The complexity behind the quantification of these damages is justified firstly by the lack of inherent standards and methodological protocols, and secondly by the different interpretations possibly given to the expert reports [3] [4] [5] [6]. The scientific literature brings several methods for assessing AFD, which vary from the subjective classification of lesions to the objective quantification of damages in severity scales. The broad variety of methods influences not only the lack of concordance in technical expertise, but also hampers a clear communication between expert reports, Lawyers, Judges and insurance companies [4]. Random and conflicting perception of AFD in between professionals involved in the legal system may lead to decisions increasingly founded on subjective evidences. The Instrument for the Analysis of Perception and Impact of Aesthetic Impairment (AIPE) [2] proposed by Cobo Plana (2010) emerged as a tool for systematic quantification of aesthetic damage. Considered particularly this methodology approach, is opportune to point that the legal device that regulates civil responsibility and insurance related to the circulation of motor vehicles in Spain (Law 35/2015) uses to assess and quantify the sequel related to aesthetic impairment a growing scale of six categories and corresponding scores in a very similar way AIPE does.

AIPES categories are defined based on increasing grades and points from: 1) not relevant lesion, zero score; 2) slight injury, values 1 to 6 points; 3) moderate, 7 - 12 points; 4) medium, 13 - 18 points; 5) important 19 - 24 points; 6) very important, 25 - 30 points; 7) truly important lesion, $31-50$ points. These scores (points) are directly transformed in economic values [2].

Considered AIPE's systematic and guided approach and the fact is being successfully used in Spain Court since 2014 (modifications RDL n 8/2015 and Law $5 / 2015^{1}$ ) and aiming to improve and better equalize the expert analysis on AFD evaluation, the present study accessed, under AIPE application, health professionals, lawyers and laypeople perceptions in a given set of cases and confronted those results (adherence) to the expected golden standard values.

\section{Methods}

The present research was approved by University of São Paulo Dentistry Scholl Committee of Ethics on June 24, 2015, under the protocol: CAAE:

43009915.2.0000.0075.

${ }^{1}$ Espanha. Ley 35/2015 de reforma del Sistema para la valoración de los daños y perjuicios causados a las personas en accidentes de circulación. Boletín Oficial del Estado, Núm. 228 de 23 de septiembre de 2015, p. 84473-84979. 
To access AFD perceptions in between health professionals, lawyers and lay people the present research worked on a convenience sample of 391 subjects in accordance to the recommended theoretical sample size.

\subsection{Inclusion Criteria}

As a pre-requisite to join this research, participants should be graduated in College and should have signed an informed consent.

\subsection{Exclusion Criteria}

Dental Surgeons specializing in Forensic Dentistry (included in previous research) [7].

Health professionals not Physicians or Dental Surgeons.

\subsection{Dynamics}

Nine sets of photographs simulating six different grade cases of AFD were provided to the participants. Each case contained images in frontal, oblique, and lateral views presented in overview and in close-up following Fernandes et al. protocol [7] (Figure 1 and Figure 2). The presentation order of the images was randomized. Within 3 minutes time interval each one was analyzed under AIPE [2] protocol, following a three-step evaluation. At the first step participants were driven, by answering a set of questions, to a preliminary approach of the AFD varying from unnoticed lesions to extremely important ones. During the second step, the evaluation consisted on answering basically three questions: 1) if the potential lesion is seen or clearly seen and if would remain in the examiners minds as an image to remember the face of the affected person; 2) if the AFD could cause an emotional response, and 3) if the emotional response itself could affect interpersonal relationship (superficially or deeply). According the answers the examiner (rater) was able to confirm or not Step 1 preliminary approach (the seven scale graduation level). The third step consisted on stratifying scores within the specific level in terms of severity (very discrete, discrete, moderate, severe and very severe). AIPE's forth step-related to the impact of the damage on sexual routine-was not applied in the present study. Scorings from 0 to 50 were obtained directly from Step 3 AFD scoring in each presented case.

\subsection{Golden Standard Values}

The golden standard values for each simulated lesion were set under a threeexperienced forensic experts' evaluation, in a process that included AIPE's author ratification, in this sense, all simulated cases were drawn considering AIPE's principles in order to correspond to a clear classification.

\subsection{Statistical Analysis}

Scorings within and between groups of professionals were compared using Chi Square tests, Student's $\mathrm{T}$ test and ANOVA with a significance level of $5 \%$. All 
tests were performed with SPSS 17.0 (IBM -Armonk, NY, USA) software package.
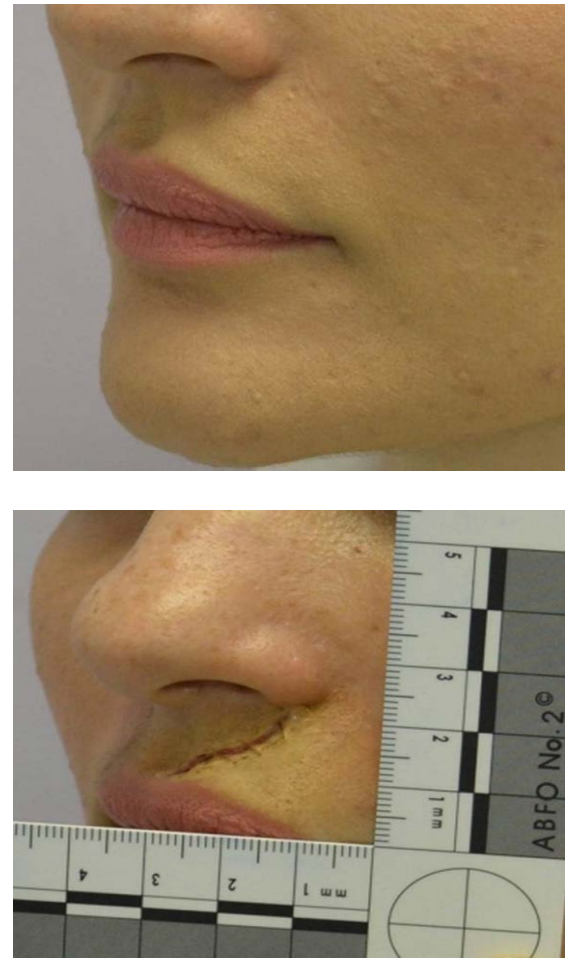

Figure 1. Illustration of the important degree (before and after).
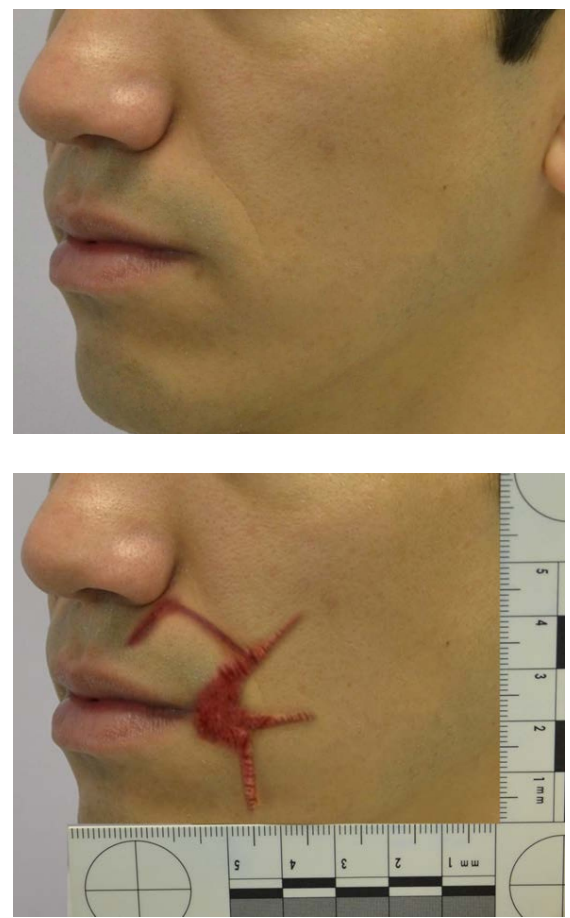

Figure 2. Illustration of the very important degree (before and after). 


\section{Results}

The sample consisted of 391 subjects (223 females and 168 males), out of which 93 were Lawyers, 93 were Physicians, 107 were Dental Surgeons and 98 were professionals out of the Health sciences and Law. The mean age of the sample was 39 years old, being $49.4 \%$ of them over 35 years age.

Table 1 summarizes severity scores adhesion to Golden Standard expected values. The frequencies are expressed as percentages of under-rating, expectedrating and over-rating. P-values express Chi Square test application. Considered the golden standard graduation, was noticed the participants tended to under-rate the lesions. Table 2 reports each lesion score adhesion under professional group. In only two lesions was observed significant variation within professional groups.

To access the 0 - 50 AFD scoring an ANOVA test was used to analyze potential perception differences in between the three professional groups. Significant variations were noticed in six of the nine lesions $(\mathrm{p}<0.05)$, being lawyers' group (G1) the one that scored less all cases (Table 3). Examiner's sex as an independent variable did not show any significant variation. When considered the examiners age group as an independent variable, ANOVA test detected a significant difference in five of the nine lesions ( 0 - 50 AFD scoring). Examiners under 35 years scored less in exception of those lesions involving severe conditions (important and extremely important ones) as seen on Table 4.

Examiners aged above 35 years tended to score AFD higher than the examiners aged below 35 years $(\mathrm{p}<0.05)$. This phenomenon occurred in 6 out of the 9 lesions, consistently the lower severity ones (Table 4).

Table 1. Severity scores adhesion considered Golden Standard values.

\begin{tabular}{ccccccc}
\hline Case & Sex & $\begin{array}{c}\text { Gold } \\
\text { Standard }\end{array}$ & Under-rated & Expected & Over-rated & $\begin{array}{c}\text { P value } \\
\text { within groups }\end{array}$ \\
\hline L1 & F & 1 & $19.4 \%$ & $47.6 \%$ & $33.0 \%$ & $0.003^{*}$ \\
L2 & F & 3 & $61.9 \%$ & $25.8 \%$ & $12.3 \%$ & 0.162 \\
L3 & F & 4 & $66.5 \%$ & $25.6 \%$ & $7.9 \%$ & 0.164 \\
L4 & M & 5 & $62.8 \%$ & $24.9 \%$ & $12.3 \%$ & 0.205 \\
L5 & F & 1 & $22.3 \%$ & $48.3 \%$ & $29.4 \%$ & 0.179 \\
L6 & M & 6 & $56.3 \%$ & $43.7 \%$ & & 0.250 \\
L7 & F & 3 & $74.9 \%$ & $17.6 \%$ & $7.4 \%$ & 0.167 \\
L8 & M & 0 & & $37.7 \%$ & $62.3 \%$ & $0.000^{*}$ \\
L9 & M & 5 & $70.3 \%$ & $20.0 \%$ & $9.7 \%$ & 0.133 \\
& & Total Mean & $54.3 \%$ & $32.4 \%$ & $21.8 \%$ &
\end{tabular}

AIPE grade scores: $0=$ not relevant lesion; 1 = slight injury; 2) moderate; 3) medium; 4) important; 5) very important; 6) truly important lesion. 
Table 2. Lesion score adhesion under professional group.

\begin{tabular}{|c|c|c|c|c|c|}
\hline & Group & Lawyers & Heath professionals & Laypeople & $\mathrm{P}$ value within groups \\
\hline \multirow{3}{*}{ L1 } & Under-rated & $29.00 \%$ & $20.50 \%$ & $8.20 \%$ & \multirow{3}{*}{$0.003^{\star}$} \\
\hline & Expected & $43.00 \%$ & $49.50 \%$ & $48.00 \%$ & \\
\hline & Over-rated & $28.00 \%$ & $30.00 \%$ & $43.90 \%$ & \\
\hline \multirow{3}{*}{$\mathrm{L} 2$} & Under-rated & $67.70 \%$ & $63.50 \%$ & $53.10 \%$ & \multirow{3}{*}{0.162} \\
\hline & Expected & $23.70 \%$ & $25.50 \%$ & $28.60 \%$ & \\
\hline & Over-rated & $8.60 \%$ & $11.00 \%$ & $18.40 \%$ & \\
\hline \multirow{3}{*}{ L3 } & Under-rated & $72.00 \%$ & $68.50 \%$ & $57.10 \%$ & \multirow{3}{*}{0.164} \\
\hline & Expected & $21.50 \%$ & $25.00 \%$ & $30.60 \%$ & \\
\hline & Over-rated & $6.50 \%$ & $6.50 \%$ & $12.20 \%$ & \\
\hline \multirow{3}{*}{$\mathrm{L} 4$} & Under-rated & $71.00 \%$ & $62.80 \%$ & $55.10 \%$ & \multirow{3}{*}{0.205} \\
\hline & Expected & $18.30 \%$ & $26.10 \%$ & $28.60 \%$ & \\
\hline & Over-rated & $10.80 \%$ & $11.10 \%$ & $16.30 \%$ & \\
\hline \multirow{3}{*}{ L5 } & Under-rated & $30.10 \%$ & $21.00 \%$ & $17.30 \%$ & \multirow{3}{*}{0.179} \\
\hline & Expected & $45.20 \%$ & $50.50 \%$ & $46.90 \%$ & \\
\hline & Over-rated & $24.70 \%$ & $28.50 \%$ & $35.70 \%$ & \\
\hline \multirow{3}{*}{ L6 } & Under-rated & $54.80 \%$ & $60.00 \%$ & $50.00 \%$ & \multirow{3}{*}{0.25} \\
\hline & Expected & $45.20 \%$ & $40.00 \%$ & $50.00 \%$ & \\
\hline & Over-rated & & & & \\
\hline \multirow{3}{*}{ L7 } & Under-rated & $78.50 \%$ & $73.50 \%$ & $74.50 \%$ & \multirow{3}{*}{0.167} \\
\hline & Expected & $16.10 \%$ & $20.50 \%$ & $13.30 \%$ & \\
\hline & Over-rated & $5.40 \%$ & $6.00 \%$ & $12.20 \%$ & \\
\hline \multirow{3}{*}{ L8 } & Under-rated & & & & \multirow{3}{*}{$0.00^{*}$} \\
\hline & Expected & $52.70 \%$ & $40.50 \%$ & $17.50 \%$ & \\
\hline & Over-rated & $47.30 \%$ & $59.50 \%$ & $82.50 \%$ & \\
\hline \multirow{3}{*}{ L9 } & Under-rated & $76.30 \%$ & $72.00 \%$ & $60.80 \%$ & \multirow{3}{*}{0.133} \\
\hline & Expected & $14.00 \%$ & $20.00 \%$ & $25.80 \%$ & \\
\hline & Over-rated & $9.70 \%$ & $8.00 \%$ & $13.40 \%$ & \\
\hline
\end{tabular}

Table 3. Mean scores by examiner's professional groups (0 - 50 AFD).

\begin{tabular}{cccccccccc}
\hline Group & L1 & L2 & L3 & L4 & L5 & L6 & L7 & L8 & L9 \\
\hline Lawyers & 4.10 & 8.14 & 13.65 & 22.64 & 3.94 & 33.15 & 5.96 & 2.43 & 20.18 \\
Heath & 4.45 & 9.15 & 14.88 & 25.05 & 4.27 & 33.30 & 7.04 & 3.22 & 22.69 \\
Laypeople & 6.86 & 11.62 & 17.26 & 26.47 & 5.67 & 35.83 & 8.66 & 6.59 & 24.33 \\
Total & 4.97 & 9.53 & 15.18 & 24.83 & 4.55 & 33.90 & 7.19 & 3.87 & 22.50 \\
$P$ & 0.001 & 0.002 & 0.006 & $0.100^{*}$ & $0.114^{\star}$ & $0.114^{\star}$ & 0.014 & 0.000 & 0.006 \\
\hline
\end{tabular}

AFD: Aesthetic facial damage; G1: Lawyers; G2: Physicians and Dental surgeons; G3: lay people; GT: total sample; L: lesion; F: female; M: male; p: p-value considering a significance rate of $5 \%$; * statistically not significant. 
Table 4. Mean scores by examiner's age groups (0 - 50 AFD).

\begin{tabular}{cccccccccc}
\hline Age & L1 & L2 & L3 & L4 & L5 & L6 & L7 & L8 & L9 \\
\hline$<35$ & 3.98 & 8.42 & 14.04 & 24.97 & 3.61 & 33.86 & 6.16 & 2.68 & 23.05 \\
$>35$ & 5.99 & 10.67 & 16.36 & 24.69 & 5.50 & 33.94 & 8.25 & 5.09 & 21.93 \\
Mean & 4.97 & 9.53 & 15.18 & 24.83 & 4.54 & 33.90 & 7.19 & 3.87 & 22.50 \\
$p$ & $0.001^{*}$ & $0.002^{*}$ & $0.004^{*}$ & 0.756 & $0.003^{*}$ & 0.936 & $0.001^{*}$ & $0.000^{*}$ & 0.223 \\
\hline
\end{tabular}

\section{Discussion}

Designed to access maxillofacial AFD perception, the present research focused, more specifically, those professionals usually involved in the forensic scenario, such as Lawyers and Health Professionals. Additionally, the perception of laypersons (represented by a group of professionals not related to Health Sciences and Law) was also investigated as being of crucial importance in such context [8].

When dealing with AIPE's scoring system is important to consider examiners perceptions over two aspects: The 0 - 6-severity graduation and the 0 - 50 valuation scale. Although both aspects are correlated, their practical purposes differ, as so differ their statistical behavior in terms of sensitivity due to scale range, and because of this, had to be analyzed in separate steps. This aspect, however, does not affect any of the results and conclusions of the research.

Participant's adherence to Golden Standards severity classification values tended to express under-rating. The mean severity classification adherence was of $32.4 \%$.

Any significant variation was observed within groups, except of lesions 1 and 8 where laypeople tended to overestimate the evaluation.

Cases $2 \& 7$, Case 3 and cases $4 \& 9$-were those that expressed the major under-rating frequencies (over a $62.8 \%$ frequency). This scenario is a matter of major concern as according to the Mapfre Foundation [9], most of the victims of traffic accidents (93\%) are affected from discrete to moderate AFD lesions.

Considered AIPES' 0 - 50 scoring system, the groups expressed different perceptions when dealing with lesions below "important" severity range. According ANOVA test, the mean values divergence in between the groups were, so, considered significant $(\mathrm{p}<0.05)$ for lesions 1 to 3 and from 7 to 9 , and not significant for lesions 4 and 6 , whose correspondences are to "very important" and "extremely important" lesions respectively.

When dealing with all cases involving different perceptions, Lawyers group was the one that rated the lower scores. One of the possible reasons behind this outcome is intrinsic to lawyers formation and practice relying on the "General Theory of Law", in which, underrating is a natural aspect of a litigant process to allow a more tangible quantification for both sides involved in a lawsuit [10]. In this context, the referred author explains that each side advocates a quantification in which proposals and counterproposals are made to reach an agreement. This process was known in Latim as "pacisci" (bargain). 
Assuming rater's sex and age as independent variables, another important aspect observed over AIPES' 0 - 50 scoring system was that while the examiners sex didn't express any significant AFD perception divergence (internally and within the groups), examiners over 35 years of age scored higher the presented lesions.

Fernandes et al. [7] had already observed the same tendency on their AFD research and have attributed this result to a longer professional and living experience of older examiners leading them to be more judicious. The effective link on being more judicious and scoring higher is far from being easily explained, but probably related to the acquired ability of transcending physical appearance evaluation to the broad perception of victims' feelings and constraints about aesthetic loss. It's a matter of being more resilient, to overpass a raw third part problem evaluation, thinking, more closely, how that same situation could affect himself (herself) in life and in society.

The observed results pointed that the health professional's valuation is in between Lawyers perceptions and Laypeople perception. Considered of fundamental importance to the forensic health professional perception, as pointed by the literature, tend to be more critical in relation to facial aesthetics [11] [12] [13] [14]. Yet this region is highly visible and often exposed for social communication justifying the need for major attention to aesthetics.

Aesthetic perception and judgement are not just cognitive processes, but also involve feelings, and studies of these experiences require conceptualization and measurement of these emotions [15]. The present study used the AIPE method and was able to analyze the feelings because it has in its methodology simple words such as memory, emotion, interpersonal relationship, and that rescue what the person is really feeling. If there is a constant search for justice for human beings, there is nothing wiser that we can introduce these feelings in the analysis and obtain fairer reports of aesthetic damage.

Transposing the perception of AFD from the scientific and academic field to the social scenario consists of a humanitarian process from which new perspectives may emerge to aid justice and society. Moreover, AFD is perceived not only in Court, but also in social daily activities [16].

\section{Conclusion}

These results recommend extra caution when performing the great majority of AFD expertise analysis. Evaluation and consequently expertise reports claim a judicious analysis based on consolidated standards. Examiners are encouraged being more perceptive to physical damage evaluation in order to include social perceptions and reactions, mainly, victim's feelings and constrains over their aesthetic loss.

\section{Conflicts of Interest}

The authors declare no conflicts of interest regarding the publication of this paper. 


\section{References}

[1] Mohan, D., Tiwari, G., Khayesi, M. and Muyia Nafukho, F. (2014) Prevenção de lesões causadas pelo trânsito: Manual de treinamento.

http://www.paho.org/bra/index.php?option=com_docman\&task=doc_view\&gid=14 95\&Itemid=965

[2] Cobo-Plana, J.A. (2010) La valoración del daños a la personas por accidentes de tráfico. Bosch, Barcelona.

[3] Rodríguez-Martínez, A., Vicente-Hernández, A. and Bravo-González, L.A. (2014) Effect of Posterior Gingival Smile on the Perception of Smile Esthetics. Medicina Oral Patologia Oral y Cirugia Bucal, 19, e82-e87. https://doi.org/10.4317/medoral.19167

[4] Rodes Lloret, F., Sánchez Navas, L.D., Borrás Rocher, F., Pastor Bravo, M. and Cañete de Silva, M. (2013) A Proposal for a Method of Forensic Medical Evaluation of the Aesthetic Damage of Scarring. Cuadernos de Medicina Forense, 19, 13-19. https://doi.org/10.4321/S1135-76062013000100003

[5] Porto, L.V.M.G., Sousa, J.R., Souza, E.H.A. and Silva Neto, J.C. (2014) Damage Quantification: The Study of Debility of Function and Permanent Deformation in the Dental Lesions. Brazilian Journal of Forensic Sciences, Medical Law and Bioethics, 4, 134-146. https://doi.org/10.17063/bjfs4(1)y2014134

[6] Valiente, A.R. and Sasot, A.V. (2014) Revisión y crítica de la valoración del daño estético. Propuesta de un nuevo baremo. Cuadernos de Medicina Forense, 20, 26-35. https://doi.org/10.4321/S1135-76062014000100004

[7] Fernandes, M.M., Cobo Plana, J.A., Bouchardet, F.C.H., Crosato, E.M. and Oliveira, R.N. (2016) Aesthetic Injury Assessment Instrument Validation in Brazil. Saúde em Debate, 40, 118-130. https://doi.org/10.1590/0103-1104-20161080010

[8] Bronowski, J. (1978) The Common Sense of Science. Harvard University Press, Cambridge.

[9] Manso, J.A. (2003) Daño estético Concepto y consideración como perjuicio. Mapfre, Madrid.

[10] Pashukanis, E.B. (2002) The General Theory of Law \& Marxism. Routledge Publisher, Abingdon.

[11] Zaidel, D.W. and Cohen, J.A. (2005) The Face, Beauty, and Symmetry: Perceiving Asymmetry in Beautiful Faces. International Journal of Neuroscience, 115, 11651173. https://doi.org/10.1080/00207450590914464

[12] Fabré, M., Mossaz, C., Christou, P. and Kiliaridis, S. (2009) Orthodontists' and Laypersons' Aesthetic Assessment of Class III Subjects Referred for Orthognathic Surgery. European Journal of Orthodontics, 31, 443-448. https://doi.org/10.1093/ejo/cjp002

[13] Shiyan, H., Xu, Q., Shuhao, X., Nanquan, R. and Xiaobing, L. (2016) Orthodontists' and Laypeople's Perception of Smile Height Aesthetics in Relation to Varying Degrees of Transverse Cant of Anterior Teeth. Australasian Orthodontic Journal, 32, 55-63.

[14] Barbosa, P.B.C., Matos, F.S., Cericato, G.O., Rosario, H.D., Pithon, M.M. and Paranhos, L.R. (2016) Perception of Laypersons and Dentists Regarding Esthetic Facial Changes: A Systematic Review. Bioscience Journal, 32, 1128-1137. https://doi.org/10.14393/BJ-v32n4a2016-32963

[15] Schindler, I., Hosoya, G., Menninghaus, W., Beermann, U., Wagner, V., Eid, M., et al. (2017) Measuring Aesthetic Emotions: A Review of the Literature and a New 
Assessment Tool. PLoS ONE, 12, e0178899.

https://doi.org/10.1371/journal.pone.0178899

[16] Bouchardet, F.C.H. and Cobo Plana, J.A. (2011) Utilización del método “AIPE” em la valoración del perjuicio estético y su aplicación em la legislación brasileña civil e penal. Revista Portuguesa do Dano Corporal, 22, 167-181.

https://doi.org/10.14195/1647-8630_22_7 